\title{
Effects of Hemoadsorption with Cytosorb during Severe Rhabdomyolysis: Reply to the Letter to the Editor of Daum and Colleagues
}

\author{
Olcay Dilken Can Ince H.R. Hilde de Geus \\ Department of Intensive Care, Erasmus Medical Centre, University Medical Center, Rotterdam, The Netherlands
}

Dear Editor,

We would like to thank Daum et al. [1] for their interest in our case report [2]. Authors raised several questions regarding the elimination of molecules, especially creatine kinase (CK), with CytoSorb.

Surgical procedures were performed before admission to the ICU, at the end of the first day and at day 2. The latter was only exploratory and no intervention was possible. During the procedures, CRRT was interrupted and restarted shortly afterward. We agree with Daum et al. that we cannot exclude the possibility of the contribution of the procedures to the trend of the CK and myoglobin. Also, ongoing ischemic insults further complicate the interpretation of the data. However, there are reports showing successful reduction of CK with CytoSorb [3-5]. Additionally, CytoSorb can initially perform more efficiently due to naïve surface area. We believe this can explain the initial fast decrease. We agree with the authors that CK exists both as a dimer and a monomer and this can be another contributing factor to the results. The definite evidence should come from pre- and post-filter measurements of the CK in the subsequent trials.

The authors also stated how we observed the saturation of the adsorber. We simply observed the noradrenaline demand and the clinical markers of shock. We were not able to measure the interleukin-6 levels.

Last, we also agree with Daum et al. that whether lowering CK is of clinical importance. Indeed, we stated in the case report that aiming the reduction of the myoglobin levels should be the priority, and fast action should be undertaken to limit the ensuing damage.

\section{Conflict of Interest Statement}

C.I. has received a grant from CytoSorb to commence a randomized controlled trial on the effect of the adsorber on the microcirculation of critically ill patients at the department of Intensive Care of the Erasmus Medical Center, Rotterdam. C.I. and his team provide services and training with regard to clinical microcirculation. To this purpose, he runs an internet site called https:// www.microcirculationacademy.org. The internet site and its activities are run by a company called Active Medical BV of which he owns shares. O.D. received a research grant from the Scientific and Technological Research Council of Turkey (TUBITAK Grant No. 1059B191800363). HRHG declare no conflicts of interest.

\section{Funding Sources}

The authors did not receive any funding.

\section{Author Contributions}

O.D. drafted the manuscript. All authors reviewed the manuscript for intellectual content. All authors agreed on the final form of the letter.

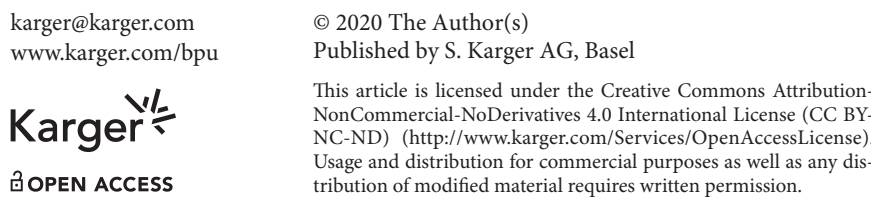

karger@karger.com www.karger.com/bpu

Karger $\stackrel{\text { ' }}{=}$

BOPEN ACCESS

\section{(C) 2020 The Author(s)}

Published by S. Karger AG, Basel

This article is licensed under the Creative Commons AttributionNonCommercial-NoDerivatives 4.0 International License (CC BYNC-ND) (http://www.karger.com/Services/OpenAccessLicense) Usage and distribution for commercial purposes as well as any distribution of modified material requires written permission.

Olcay Dilken

Department of Intensive Care, University Medical Center Rotterdam

Doctor Molewaterplein 40

NL-3015 GD, Rotterdam (The Netherlands)

olcaydilken@gmail.com 


\section{References}

1 Daum HC, Schmidt BMW, Napp LC. Effects of hemoadsorption with CytoSorb during severe Rhabdomyolysis. Blood Purif. 2020. DOI: $10.1159 / 000508277$.

2 Dilken O, Ince C, van der Hoven B, Thijsse S, Ormskerk P, de Geus HRH. Successful reduction of creatine kinase and myoglobin levels in severe rhabdomyolysis using extracorporeal blood purification $\left(\right.$ CytoSorb $\left.^{\circledR}\right)$. Blood Purif. 2020:1-5.
3 Suefke S, Sayk F, Nitschke M. Hemoadsorption in infection-associated rhabdomyolysis. Ther Apher Dial. 2016;20(5):531-3.

4 Immohr MB, Lichtenberg A, Boeken U, Akhyari P. Succesful treatment of a severe case of rhabdomyolysis following heart transplantation by hemoadsorption. J Card Surg. 2020;35(4):940-1.

5 Padiyar S, Deokar A, Birajdar S, Walawalkar A, Doshi H. Cytosorb for management of acute kidney injury due to rhabdomyolysis in a child. Indian Pediatr. 2019 Nov;56(11):974-6. 